I.G.Y.

Year of Discovery-The Story of the International Geophysical Year. By Sydney Chapman. Pp. 112. (Ann Arbor : University of Michigan Press ; London : The Mayflower Publishing Co., Ltd., 1959.) 40s.; 4.95 dollars.

T HE International Geophysical Year, July 1, 1957 December 31, 1958, was the most successful example of co-operation between the nations there has ever been, and as well as being a landmark in the development of geophysics it may well be of significance in the present endeavours to increase international understanding. In his account of this enterprise, of the executive committee of which he was president, Prof. Sydney Chapman records how at first there was little enthusiasm for a successor to the two international polar years and then how the interest grew until International Geophysical Year committees from sixty-seven countries joined in and a wide variety of geophysical projects were undertaken, to be climaxed by the launching of the first Earth satellite on October 4, 1957.

But the book is not an account of the organization of the International Geophysical Year, important though this was. It is an excellent account of the scientific background of and the reasons for the projects undertaken.

Those familiar with Prof. Chapman's writings will not be surprised to know that this book is a model of scientific writing; the sentences are short and not encumbered by unnecessary words; a large number of useful facts about the Earth are to be found in the text; plates and diagrams illustrating the whole field of activity are included. It can therefore be recommended to students and to laymen who wish to acquaint themselves with what is known about the Earth, and there will be few, even among experts in geophysics, who will not learn something by reading it.

S. K. RUNCORN

Progress in Semiconductors, Vol. 4

Edited by Dr. Alan F. Gibson, Prof. R. E. Burgess and Dr. F. A. Kröger. Pp. vii +291. (London : Heywood and Co., Ltd., 1960.) 63s. net.

THE series of review articles which make up the volumes of "Progress in Semiconductors" help very much to cut down the time which physicists, chemists, metallurgists and electronic engineers in this still rapidly expanding field have to spend reading the journals less familiar to them. Unfortunately the series can survey the whole field no more frequently than perhaps once every ten years.

The eight papers which make up the fourth volume are generally well written but expect quite a lot from the reader. The easiest to read are those on the oxidation of germanium surfaces (the Mott-Cabrera mechanism is ruled out for a clean surface), on internal field emission, which has been studied in $p n$ junctions and in phosphors, and on the electrical effects of dislocations. In contrast a paper on negative mass demands some familiarity with quantum mechanics and another on avalanche multiplication demands confidence in expressions for the motion and scattering of electrons in high fields. A paper on noise in semiconductors shows that the components with spectral intensity $\propto$ (frequency $)^{-1}$ still need further study. The effect of dislocations on dielectric properties is studied in another paper in terms of ion movements, electron trapping and microwave observations. The last paper, of which A. F.
Ioffe is co-author, directs attention to a large range of non-crystalline semiconductors, including liquids, in which the carrier motion is very different from that in germanium and silicon.

J. R. Tillman

\section{Comprehensive Inorganic Chemistry}

Edited by Prof. M. Cannon Sneed and Prof. Robert C. Brasted. Vol. 7 : The Elements and Compounds of Group IVA. By Harold P. Klug and Prof. Robert C. Brasted. Pp. ix +302. (Princeton, N.J.: D. Van Nostrand Company, Inc. ; London : D. Van Nostrand Company, Ltd., 1958.) 56s. $6 d$.

HIS book is one of a series in which an attempt has been made to combine an encyclopædic treatment of the chemistry of the elements with the inculcation of the basic principles of chemistry. When one considers the extent and complexity of inorganic chemistry to-day, it is clear that a good deal of information must necessarily be omitted if a whole group is to be covered in a volume of this size. For example, the historical background of each element is cut to a minimum (but Cornish tin (page 212) certainly reached Rome before the Roman conquest of Britain), and it is, perhaps, a little surprising that the uses of carbon-14 are scarcely mentioned and, in view of their uses in atomic energy, some reference might well have been made to cadmium and cerium glasses. However, the descriptive chemistry of the elements covered in this volume is presented lucidly and the result is a not unpleasing text-book which should be useful to the university student and to the research chemist, for whom the numerous tables of physical data will be of considerable value. The book is well produced, and the index, so far as tested, is adequate.

K. W. Bagnall

\section{Histochemistry}

Theoretical and Applied. By A. G. Everson Pearse. Second edition. Pp. $x+998+10$ plates. (London: J. and A. Churchill, Ltd., 1960.) $110 s$. net.

7 HIS is a vast guide-book to the fields of histochemistry. Twenty-nine chapters and twentyseven appendixes provide a comprehensive and up-to-date account of the subject. In the spirit of "Baedecker" the author has practised all the available methods and rejected those found wanting. This enormously enhances the value of the book, but had the further step of a star system been taken to classify the many methods, the novice would be better served. There have been so many improvements and extensions since the first edition of seven years ago that this is virtually a new and better book.

The chemical and physical backgrounds to the techniques have been given so far as is practicable in a book of finite size. Readers with special knowledge of the various aspects of the subject will no doubt find omissions, misunderstandings and misplaced emphasis, but I have found no serious cases in my own special fields. With this volume as a guide, cytochemists can travel hopefully but might be more sure that they would arrive safely if an extended and quantitative account of the hazards and errors of interpretation due to diffusion during fixation and reaction had been provided. The illustrations, especially the colour plates, make this an attractive book to use, but have undoubtedly added to its high cost. Inexcusably the book is shoddily cased, and with a covering unlikely to withstand the hard use this book will undoubtedly have in all histochemical laboratories.
L. G. E. BELL 